\title{
Construcción de la alteridad y el significado de la familia en las ventas ambulantes
}

Karla Vega

Antropóloga independiente kantr.vega@gmail.com

Resumen: El presente artículo analiza la construcción de la alteridad en dos familias de vendedores ambulantes que laboran en la ciudad de San José, Costa Rica y cómo manejan dicha construcción en la coyuntura económica y social que enfrentan actualmente. Para la recolección de los datos, se utilizó el método etnográfico y las entrevistas no estandarizadas para evitar interrumpir las labores de los vendedores. Se encontró que la economía popular es más que un medio para obtener recursos, es una estrategia para las familias que la emplean, la cual involucra la dinámica social, comunal y familiar; las y los vendedores ambulantes se constituyen en una gran familia con funcionamiento propio.

Palabras clave: Antropología Urbana, alteridad, familias, ventas ambulantes, San José.

The set of alterity and the meaning of the family within the street sales

Abstract: This article analyzes the construction of the alterity in two families of street sellers working in San Jose downtown, Costa Rica and how they face the economic and social situation nowadays. The Ethnography and not standardized interviews were used to collect data to avoid disrupting of the sellers' work. It was found that the popular economy is not only a way for obtaining resources; it is also a strategy to the families who uses it, which involves social, community and family dynamics. The street sellers constitute a large family with its own performance.

Keywords: Urban Anthropology, alterity, families, street sales, San Jose.

Cuadernos de Antropología

Enero-Junio 2015, 25(1), 25-46

DOI: $10.15517 /$ cat.v25i1.18796

Recibido: 12-07-2014 / Aceptado: 24-03-2015

Revista del Laboratorio de Etnología María Eugenia Bozzoli Vargas

Escuela de Antropología, Universidad de Costa Rica

http://revistas.ucr.ac.cr/index.php/antropologia

ISSN 2215-356X

c) (1) (-) Cuadernos de Antropología está bajo una licencia Creative Commons Attribution-NonCommercial-ShareAlike 3.0 


\section{Introducción ${ }^{1}$}

Este documento analiza la construcción de relaciones de alteridad en dos familias de vendedores ambulantes que laboran en el centro de San José (Costa Rica) y cómo las manejan en coyunturas tan diversas como las que encuentran cotidianamente. Se enfatiza en las dinámicas de la economía popular y la permanencia en las calles mientras realizan su trabajo. Para lo anterior, se desarrollaron genealogías narradas, desde donde se estudió el contexto familiar y laboral.

Tanto la genealogía como la etnografía permiten un acercamiento más directo a las realidades de la población estudiada. Por su parte, la genealogía es especialmente importante, ya que permite identificar cómo ha acontecido la actividad económica de generación en generación como parte del capital social de estas familias. Por otro lado, la etnografía permite conocer de primera mano los procesos de construcción de las relaciones de los vendedores ambulantes.

A través del trabajo de campo etnográfico, se constató que las ideas acerca de la familia y su preponderancia varían entre los actores de este contexto y, en algunos casos, la familia y el trabajo van tan de la mano que un compañero laboral es a la vez el cuñado o la hermana. Además, se constató que la familia es una estrategia en sí misma para hacer frente a las condiciones que la ciudad les presenta con respecto a su actividad económica, pues el contexto social ha empujado a los miembros de diferentes grupos familiares a convertirse en aliados no solo para la vida sino para el trabajo.

Este ensayo consta de dos apartados. El primero aclara lo que se entiende por construcción de la alteridad por parte de los vendedores ambulantes $\left(\mathrm{VA}^{2}\right)$. Se reflexiona acerca de la individualidad y la pertenencia a un contexto específico y de cómo las familias manifiestan la constitución de personalidades únicas. El segundo aborda el concepto de familia y su significado en la actualidad. Se hace un recorrido por los cambios que ha experimentado el concepto y de cómo se apropió dentro de esta investigación. Por último, se presenta una sección de conclusiones.

Los sujetos de estudio fueron los integrantes de dos familias de vendedores ambulantes, los criterios de selección fueron: 1) que se dedicaran a la venta de productos vegetales en las cercanías del Mercado Central y Borbón, ubicados en la capital de San José, avenida 0, calle 8, y 2) que además tuvieran al menos 2 miembros de su familia involucrados en la economía popular, como único medio de obtener recursos.

1 Este artículo es resultado de uno de los capítulos del seminario de graduación para optar al grado de licenciatura en Antropología, tituado Experiencias, vivencias e identidad de quienes se dedican a la venta ambulante de frutas y verduras, ubicados en las calles 6 y 8 del casco urbano central de San José, 2010-2011 (Araya et al., 2011)

2 De acá en adelante se utiliza la sigla VA para refería más expeditamente a "Vendedores Ambulantes".

Cuadernos de Antropología 2015, 25(1), 25-46 / ISNN 2215-356X

http://revistas.ucr.ac.cr/index.php/antropologia 
Dentro de los participantes principales de la investigación se encuentran ${ }^{3}$ :

- Lucía de 19 años, hija de una vendedora ambulante; tiene 9 hermanos, algunos de los cuales aún ahora son VA. Sus dos niñas y su niño la acompañan en la calle cuando no es posible que alguien los cuide. Un dato importante es que el encarcelamiento de la madre de Lucía coincidió con el tiempo cuando se realizó el trabajo de campo.

- Carlos de 20 años es hijo de un vendedor de lotería de San José, su madre falleció en 2005, es pareja de Lucía. Dos de sus hermanos son VA como él y se ubican cerca para vender.

- Conrado tiene 47 años y es padre de dos jóvenes entre los 20 y los 30 años. Se encuentra casado desde hace 27 años, vive con su esposa y sus hijos.

- La Machita cuenta con 65 años de edad y más de 50 de ser vendedora. Es madre de 8 hijos, uno de ellos es Conrado. Se ubica en los alrededores del Mercado Borbón para vender chiles dulces.

La investigación se desarrolló en las cercanías de los puestos de trabajo de los y las participantes. En cada caso, se trabajó con los vendedores y vendedoras sin interrumpir sus labores para captar la dinámica de la economía popular ahí donde se lleva a cabo.

El estudio se extendió desde junio de 2010 y continuó hasta marzo de 2011. Las experiencias relatadas corresponden tanto a las vivencias experimentadas durante el desarrollo de la investigación como a las que los informantes narraron de años anteriores. Se utilizó la observación no participante y entrevistas no estructuradas para recabar datos con mayor detalle; además de la genealogía narrada como herramienta primordial para recabar los datos.

\section{Construcción de la alteridad}

La palabra alteridad deriva del latín alter (el otro); puede decirse que es el principio filosófico de "alternar" o cambiar la propia perspectiva por la del "otro", el reconocimiento de las singularidades del otro; tiene que ver con la experiencia de lo extraño y esta se dirige hacia aquellos que nos parecen tan similares a nosotros mismos que toda la diversidad observable puede ser comparada con lo acostumbrado, y que, sin embargo, son tan distintos que la comparación se vuelve reto teórico y práctico (Krotz, 1994).

Por tanto, la capacidad de interiorizar al otro y valorar los puntos conciliables entre mi discurso y mi identidad y la del otro es la alteridad. En dicho sentido, los seres humanos están constantemente creando procesos de reconocimiento del otro y de sí mismos frente a esos otros.

3 Todos los nombres usados son seudónimos y no corresponden con los nombres reales de los participantes, esto para garantizar su anonimato. 
El término alteridad se aplica al descubrimiento que el "yo" hace del "otro", lo que hace surgir una amplia gama de imágenes del otro, del "nosotros", así como visiones múltiples del "yo". Tales imágenes, más allá de las diferencias, coinciden todas en ser representaciones más o menos inventadas de personas que comparten el mismo universo social. Surge como la idea de ver al otro teniendo en cuenta sus creencias y conocimientos, para esto es necesario un acercamiento que permita el diálogo y la comprensión.

En medio de contextos y situaciones específicas, cada ser se ve a sí mismo con respecto al otro, con el cual tiene vivencias en común, al igual que las familias, tanto los individuos solos, como en grupos, construyen relaciones de alteridad, pero que de igual manera buscan la diferenciación, así como una personalidad única.

El Otro en el caso de las familias de VA es parte del mismo entorno y se encuentra cara a cara en la construcción de la alteridad. Este reconocimiento y extrañamiento de los propios miembros de la familia y la reconciliación constante que debe de existir entre los discursos de los miembros permite que se palpen más claramente las opiniones y las conciliaciones que hacen los vendedores entre sí, con sus familias y sus pares. El Otro, ese a partir del que también se construye la alteridad, es en las familias de VA, hermano, hermana, madre, padre, hijo y extraño.

Cada persona es capaz de auto-reconocerse y de interpretar los signos de quienes le rodean, además de percibir las transformaciones en el comportamiento tanto a pequeña como a gran escala. Además de ello, cada sujeto o ego está en condiciones de generar cambios en la forma en que se organizan y regulan las relaciones con los otros, sean estos su comunidad, sus conciudadanos o su propio núcleo familiar. De allí que sea vital reconocer cómo es la visión que tiene cada persona de los propios miembros de la familia de la cual es parte y cómo se relaciona con sus integrantes, es decir, cómo se plantea la alteridad familiar. Al referirse a las limitaciones que debió enfrentar desde pequeño uno de los vendedores, este dijo: "Pero estas situaciones lo hacen a uno valorar el sentido de la responsabilidad, que las cosas no vienen por venir, sino que uno tiene que esforzarse por tenerlas. Mis hijos vienen a trabajar aquí porque tienen sus responsabilidades" (Conrado, comunicación personal, 30 de marzo 2011).

Las relaciones con el grupo familiar entonces estaban basadas en las responsabilidades adquiridas por ser una familia numerosa en la cual las actividades del hogar, como las de la crianza, se repartían entre todos. Siguiendo los patrones establecidos, se puede deducir que se espera que se reproduzcan aquellos asociados con el honor y la dedicación hacia el otro, sin importar lo que se necesite para construir el bienestar de todos los miembros. Así, Conrado sigue contando que su papá:

En diciembre nos llevaba a Zapote o plaza Víquez y a nosotros nos decía: espérense que voy a ir a sacar plata del banco, y yo decía "jueputa, mi papá tiene plata en el 
banco", y a los años me di cuenta que del banco que sacaba la plata era del banco de sangre... Vendía sangre para llevarnos a pasear a nosotros. No me provoca melancolía ni nada, sino que me siento orgulloso de mi papá, que si no era de una manera, era de otra que buscaba salir adelante con nosotros (Conrado, comunicación personal, 30 de marzo, 2011).

Contar con un padre que le mostrara el sacrificio y el esfuerzo, según sus propias palabras, le dio valores firmes y alega que "eso lo forma a uno como persona con una moral y unos principios muy elevados, que no es cualquier cosa que lo puede a uno desviar de los principios que uno tenga" (Conrado, comunicación personal, 30 de marzo 2011). Desde la perspectiva de la alteridad, Conrado tomó los valores que asocia con su padre (honor, dedicación, sacrificio y esfuerzo) y los hace suyos como modo de vida. Reconoce cuáles son los aportes que su padre significó como figura dentro de la familia y los extrapola a la suya.

Por otra parte, en el caso de Lucía, quien también proviene de una familia numerosa, considera que lo más sobresaliente acerca de sus familiares fue que se pusieron en su lugar cuando aparecieron situaciones difíciles, como cuando ella dice: "quedé embarazada a los 15 , lo aceptaron de buena manera y me ayudaron, entonces nada que decir de ellos" (Lucía, comunicación personal, 30 de marzo, 2011). Desde aquí, ella construye sus relaciones de alteridad familiar, ya que en vez de ser juzgada y rechazada, se adoptó a una posición de acogimiento y ayuda, lo que para Lucía significó mucho.

Lo anterior armoniza con la idea de que el desarrollo personal se ve altamente influenciado por las relaciones familiares, por lo que la importancia que se le sigue asignando a las relaciones que ahí se establecen debe de estudiarse de manera crítica, a la luz de los cambios históricos y económicos en los que se generan. Se puede decir que, en efecto, la persona es, en esencia, un ser de relación. Se realiza en la medida en que se relaciona con el otro, y se frustra en la medida en que no lo logre (Gonzáles, 2007).

La alteridad consiste en conocer el proceso mediante el cual los integrantes de una familia se explican quiénes son los otros en su vida. Ahora bien, se evidencia que a partir de una reflexión interior surja la socialización y los modelos o patrones de relación familiar. En el grupo familiar ese otro se explica desde los vínculos construidos por la cercanía y por las experiencias compartidas, pero a la vez es un otro distinto que actúa por principios propios y creencias particulares que provocan al interior del grupo, un grado de extrañamiento, pero ese otro no deja de ser semejante por la base de valores comunes. Parte de lo que a la construcción de la alteridad se refiere es cómo actúan los otros en cuya compañía se interactúa y con los cuales se es comparado y qué identidades alternativas y conjuntos de normas están disponibles para el individuo (Barth, 1976). 
Las experiencias a las que hacen referencia los vendedores corresponden a las vividas en las familias que han formado y, en menor medida, a las familias de origen. En el caso de Conrado, quien tiene 27 años de casado, la explicación de quién es el otro en su vida se basa en los roles preestablecidos, donde cada miembro es, en sí mismo, un agente pasivo, que está en la familia para cumplir con ciertos cánones. No obstante, en cuanto uno de los miembros decide dejar de seguir los patrones establecidos, como los que debería cumplir Conrado, le causa un desbalance en su concepción del otro, el asombro que le producen las decisiones de su esposa acerca de trabajar fuera de la casa hacen que esta pierda la imagen que él conserva de lo que debería ser una esposa y lo expresa diciendo: "Y yo le digo una cosa, si la doña trabaja es porque quiere, no porque ocupa; si tuviera una meta, yo no lo vería mal, pero trabajar por trabajar" (Conrado, comunicación personal, 30 de marzo, 2011).

Por un lado, Conrado valora su trabajo como una actividad que le gusta y le da realización, pero el trabajo de su mujer fuera de la casa no es justificable bajo los mismos parámetros, pues según su idealización de la esposa, esta no debe estar fuera de las fronteras de la casa. Aun así para mantener la convivencia con ella, debe acoplarse a su decisión y entender sus razones para hacerlo.

El caso de Lucía es diferente, para ella los roles y nombrar su relación con Carlos es algo de lo que no está pendiente y que además le produce, hasta cierto punto, un desfase entre lo que dice ser y lo que realmente quiere ser: "Nunca digo que soy esposa de él, siempre digo que es el papá de mi bebe, pero se siente raro, me siento que soy muy joven para eso" (Lucía, comunicación personal, 30 de marzo, 2011).

Aunque Lucía está en una relación estable con Carlos, no se siente a gusto con la idea de ser nombrada como la esposa de, lo que se puede deber a la idea que maneja de lo que significa esa posición, y su relación con Carlos está mediada por las circunstancias del hijo que tienen juntos y no por las cuestiones sociales que se atribuyen al matrimonio; además, ella se siente parte activa de la familia que aporta dinero y su trabajo. La concepción de la mujer que espera a su esposo en casa cuidando de los niños no es algo con lo que Lucía se identifique.

No todo es la relación con la pareja, sino que existen figuras que por su papel en la vida de los informantes aún ocupan un lugar dentro de las experiencias que ellos recuerdan; Lucía y Conrado tienen formas distintas de relacionarse y entender a sus madres, mientras para Lucía es una figura "buena, cariñosa atenta, todo lo tiene" por quien "daría su vida porque ella no estuviera en la cárcel, es inexplicable" (Lucia, comunicación personal 30 marzo 2011); para Conrado esta misma figura representa la autoridad y el modelo de vida a seguir por su sacrificio, resume su relación con ella en la siguiente cita: "Yo vivo a tres casas de la de mi mamá y no la visito porque visitarla es para que diga: 'nada más vienen a ver que se comen', usted sabe cómo son las mamás que si las visitás por qué las visitás y si no, porque no nunca se les queda bien" (Conrado, comunicación personal, 30 de marzo, 2011). La alteridad se construye a través de ese extrañamiento, Conrado acepta que su madre tiene esa forma de expresarse, que en realidad en el fondo se preocupa de sus hijos y que le da gusto verlos. 
En el caso de la relación de Conrado con sus hijos se da el mismo fenómeno arriba descrito. Aunque los hijos de Lucía están en una etapa de crecimiento muy distinta a la de los hijos de Conrado, para ella sí es importante que las niñas le cuenten cómo van en el kínder donde asisten, esto lo expresa diciendo: "A mí me tiene super contenta, cada vez más realizada con mis hijas cuando llegan del kínder y me cuenta que hizo esto y esto, me tienen super realizada los tres" (Lucía, comunicación personal, 30 de marzo, 2011).

Para Conrado, que sus hijos le comenten sus asuntos es entrometerse en las relaciones que ellos establecen, por ejemplo dice:

Ni con mis hijos a veces llegan a contarme papi es que Susana que es la novia de uno de ellos, y yo le digo "vea papito, yo en sus problemas sentimentales no me meto, porque si le doy un consejo usted no va a hacer caso, si yo le digo a usted ahí no vaya porque hay un hueco usted más rápido se va". El problema es que hay que dejarlos que experimenten por cabeza propia (Conrado, comunicación personal, 30 de marzo, 2011).

Sin embargo, la alteridad no solo está en la manera de ver al otro e interiorizarlo, sino que desde una visión amplia de esta categoría -la alteridad- se halla en la manera ética de convivir con los demás, es aquí donde juega el respeto por las diferencias y la búsqueda de conciliación entre lo que se espera del otro y lo que realmente hace. Del respeto de la identidad del otro nace una convivencia más o menos armoniosa que permite el mirar a ese otro no en términos de la lejanía, sino desde la convivencia. La alteridad es el trato con el otro, "mi relación con el otro" igual, pero distinto, que incluye la capacidad ética de reconocerlo y responsabilizarse de quién es, de lo que hace o desea. Los procesos de diferenciación en el núcleo familiar se basan, entonces, en la experiencia de lo extraño. Se trata del reconocimiento de cada uno de los miembros en el yo, visto desde lo desconocido.

En el ámbito familiar, la alteridad nace de la tensión que cada sujeto tiene con otros miembros, es producto de la negociación que cada uno realiza para recibir las normas de los demás miembros y sus percepciones acerca de dichas normas. La alteridad dentro de la familia, entendida como la identificación de la diferencia del otro, le permite a esta reconocer o no al otro en su dignidad y derechos, etc. Cuando es el caso de los hijos que llegan a la adolescencia, la familia completa enfrenta un periodo de ajuste. "Nunca tuvimos problemas chiquitillos no, pero cuando crecimos sí, por diferencia de opinión”, (Conrado, comunicación personal, 30 de marzo, 2011), aunque Conrado reconoce que las tensiones alrededor de las discusiones entre él y sus hermanos, y los desencuentros por las distintas labores que debían realizar, en su momento no fueron sencillas de llevar, dice que no provocaron grandes conflictos. Lo que les permitió crecer reconociendo las diferencias de unos y otros y asimilarlas con el paso del tiempo.

La importancia de comprender cómo se vive este proceso en la familia reside en que la mayoría de los recursos, de los cuales los individuos disponen para definir sus relaciones humanas y sociales, es derivada 
de los vínculos que se establece con los miembros de su entorno de origen. Se puede decir que en los casos estudiados, la socialización pensada desde el otro, en función de los roles preestablecidos y desde unas condiciones de decisión muy limitadas, en cuanto a la escogencia de trabajo dentro de su familia de origen, marcó una pauta para las relaciones posteriores. A su vez, dichas relaciones influyen la formación de creencias, hábitos e indicadores de riesgo para definir actitudes y conductas frente a la alimentación, las relaciones interpersonales, el entorno social y ambiental, la enfermedad y la muerte, entre otros. Por lo tanto, la manera en que se piensa el entorno y cómo se educa a los miembros de las familias en cuanto a las relaciones con los otros (ver Cuadro 1) van a marcar la manera en que se conciben las demás relaciones sociales, los parámetros con los cuales cada individuo va a ver a sus otros significantes, dependerá de cómo se manejaban al interior de la familia.

En términos antropológicos, la alteridad es vista como la capacidad de ser otro, de alternar, de tomar o ponerse en el punto de vista del otro. Es también la capacidad de reflexionar sobre uno mismo, a partir de la visión y el conocimiento que se tiene del otro; en ese sentido, estamos hablando de una alteridad dialógica.

En los VA, la alteridad, como proceso dialógico, es resultado de las relaciones del yo (sujeto objeto) consigo mismo, pero a su vez también con la alteridad del otro o de muchos otros. La identidad se construye a partir de cuatro tipos de relaciones: la del yo consigo mismo, la percepción interna del yo, la imagen que el yo tiene del otro y la imagen que el otro tiene del yo. Ese conjunto de relaciones constituye la identidad social de los sujetos construida y determinada por la alteridad del otro (Alejos, 2006).

En las familias, la alteridad nace de la conciliación de la diferencia, pues se acepta que cada miembro es en sí mismo distinto en gustos, deseos y proyectos, pero cada una de las personas que comparten el vínculo familiar tratan, en mayor o menor medida unos y otros, de entender esas diferencias y respetarlas, aunque esto cueste alguna que otra contradicción a lo interno del grupo familiar.

La alteridad familiar nace entonces del punto medio de dos o más discursos que, aunque son diferentes entre sí, pueden reconocer que existe algo de legítimo en cada cual, por lo que se interioriza aquello que cada uno considera como válido y se relega lo que no lo es, dando como resultado un nuevo discurso en el cual caben los demás a pesar de ser inicialmente distintos. Al ser una temática poco común, se presentan escasos instrumentos para estudiarla. Por esto se plantea la necesidad de abordarla desde nuevos medios que sean capaces de comprender la calidad de la interacción entre los miembros y permitan conocer realmente la dinámica familiar. Entendiendo que la familia es producto de la construcción social e histórica y que se encuentra en constante cambio, pues las condiciones en las que se desarrolla pueden pasar de lo estable a la crisis de forma constante. En la figura 1 se ilustran algunos de los aspectos presentes en la construcción de la alteridad en la familia.

Se pueden entender de esta manera: Lealtades, fuerza que tensa las relaciones del grupo y les exige cambio. Apoyo incondicional en las situaciones difíciles como embarazo adolescente o fallecimiento de 
Cuadro 1: Concepto de alteridad (modificado de Araya et al., 2011).

\begin{tabular}{cc}
\hline $\begin{array}{c}\text { Procesos que acontecen al interior de las relaciones sociales de reflexión, re-conocimiento y construcción de otras personas en } \\
\text { las familias de Vendedores Ambulantes }\end{array}$ \\
\hline $\begin{array}{c}\text { Tienen efectos sobre cómo se ve a los otros } \\
\text { Reconocer a otras personas como distintas a sí misma (separar) (con } \\
\text { puntos de vista, pensamientos, actitudes distintas a las propios) } \\
\text { Reconocer a otras personas como parte de uno mismo } \\
\text { (acercar-identidad) }\end{array}$ & Reconocerse a uno mismo como distinto de los otros \\
Imágenes que se construyen al descubrir al otro. & Imágenes que se hacen de uno mismo al descubrir al otro \\
\hline
\end{tabular}

uno de los miembros.

a) Valores: corresponden al pensamiento familiar. Responsabilidad y honestidad que marcan la pauta para trabajar y vivir.

b) Creencias: presupuestos que constituyen lo que es verdadero o falso para esa familia. Las ideas de los egos en este sentido se enfocan en que las formas en las que sus antecesores vivieron les dieron las herramientas para ser lo que son.

c) Mitos: sirven para encubrir una realidad dolorosa que no se explica conscientemente. Explicaciones mágico-religiosas acerca de la realidad de uno de los miembros de la familia.

d) Ritos o rituales: sirven para transmitir los mitos y señalan transiciones del núcleo familiar. Formas de disciplinar y educar.

e) Legados: fenómenos que revelan a las siguientes generaciones los principales aspectos de la familia actual y que se esperan tengan continuidad. Constante socialización con el contexto de trabajo, en medio del cual se reafirman los valores familiares.

f) Secretos: se trata de esconder hechos o sentimientos que no corresponden a los patrones familiares (la adopción, por ejemplo) (Gonzales, 2007). En este caso, se presenta la evasión de la conversación acerca del encarcelamiento de la madre de una de las entrevistadas.

Para Lucía, la lealtad de su grupo familiar se presentó cuando de adolescente quedó embarazada; para ella fue la demostración de que la ayuda incondicional podía presentarse en su familia, por este motivo, en la actualidad ella está dispuesta a retribuirle.

Conrado hizo suyos los valores que en su vida familiar sus padres reprodujeron y los lleva hasta su propia familia, lo que marca la forma en la cual se relaciona con sus hijos y esposa y desde ahí los ve como esos otros iguales, pero distintos.

En el contexto de trabajo de los VA, la cooperación, la solidaridad y la lealtad nacen del encuentro de los valores reproducidos por cada uno, como parte de entender a ese otro cercano y sus circunstancias, to- 


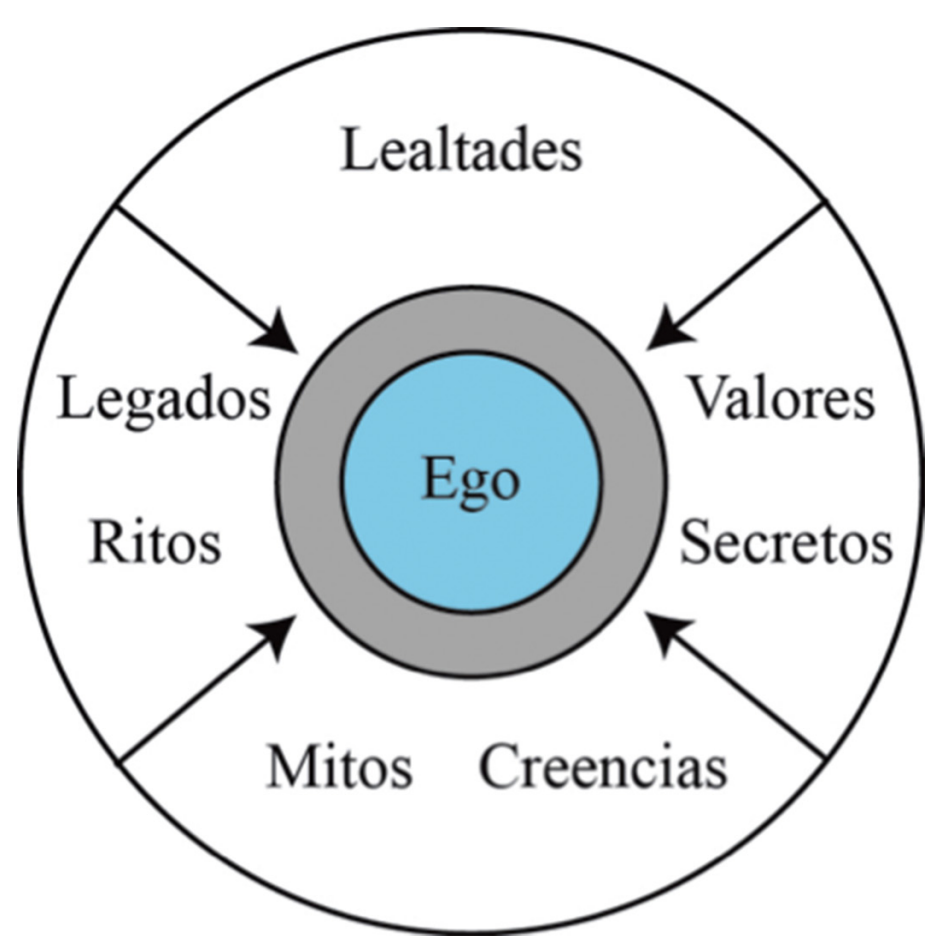

Figura 1: Construcción de la alteridad del ego (tomado de Araya et al., 2011).

dos saben lo que es ser vendedor y por eso se logran poner en los zapatos del otro. Dicho encuentro puede verse como un medio de supervivencia porque prevalece a pesar de las alteraciones que se dan dentro del ambiente en el cual conviven.

Las formas que toma la subjetividad (microcosmos) en el plano de lo social (mundo) son acciones objetivas que son percibidas por el conjunto social en el que las familias de VA están inmersas. Debido a la proximidad y cotidianidad con la que el ser humano hace el traslado de un ámbito a otro, se produce la falsa impresión de que el sentido común es suficiente para entender lo que sucede al interior de la familia, es por esto que debe existir un constante extrañamiento de lo cotidiano y dejar de lado las suposiciones comunes.

En el proceso de conocimiento de la alteridad familiar es necesario ser empático con quienes se trabaja (Lévinas, 1993). Por este motivo, para su análisis, el investigador debe de salirse de sí mismo para conocer realmente lo que sucede en el seno familiar de ese otro que estudia y reconocer que la alteridad es el relieve del otro frente al otro cuando el otro está dado. Según el psicólogo Freddy Gonzales (2007), se trata de un ejercicio a nivel subjetivo y cualitativo entre egos, pero que tiene efectos sobre las prácticas concretas de las personas, en especial en las laborales.

En el caso de los VA, se tiene claro que para lograr comprender en detalle sus formas de vida es necesario despojarse de la mirada de la exclusión impuesta por el discurso dominante; donde el VA ocupa el 
lugar del bárbaro, y la imagen que se ha creado de él es construida a partir de estigmas. El VA se convierte entonces en un ser tan lejano que provoca miedo y desconfianza, lo que es el motor del rechazo que sufren en la sociedad.

El nivel de interacción con las personas en el ambiente de la calle debe generar el mayor grado de confianza para acceder a las estrategias para llevar a cabo la actividad económica. Cabe decir en este punto que para algunos los límites entre lo doméstico y el trabajo se han diluido y existen expresiones como "la calle es como mi casa" (Lucía, comunicación personal, 7 de febrero, 2011), por lo que la agudeza a la hora de mirar el espacio de trabajo donde se encuentran los VA debe ser muy grande. Dicha agudeza ayudó a diferenciar los momentos en los cuales los VA ubicaron a otras personas quienes no tienen filiación sanguínea o familiar en el mismo plano de los que sí lo son; lo que puede deberse a la calidad de las relaciones existentes y al vínculo de reciprocidad extendido, que nace a partir de la solidaridad y que se propicia en la calle durante el trabajo.

Desde esta perspectiva, se puede señalar que la alteridad familiar se produce entre el sistema de relaciones (endógenas) de un grupo familiar, pero además la producción de alteridad se haya influida por las relaciones (exógenos) presentes en los sistemas que rodean la familia (Gonzales, 2008). El conjunto de relaciones objetivables y subjetivables entretejidas dentro del sistema familiar dieron cabida a la indagación desde la alteridad, lo que llevó al análisis desde dos escenarios: el endógeno o la dimensión cognitiva, y el exógeno que se manifiesta en las interacciones sociales observables entre las que se cuentan rostros de agrado, hábitos de interacción afectiva, asertividad. Lo visto es la construcción de proxemia en la familia mientras interactúa, ya sea con otros o con los miembros del núcleo familiar.

Por otra parte, existe la alteridad construida en el seno de la propia familia, en el mismo núcleo de aquellos que la componen. En este plano, se observan las relaciones erigidas entre los padres e hijos, entre los hermanos y entre los propios padres (si es que están presentes y tienen una relación). Cada miembro complejiza el contexto en el cual se dan las relaciones por medio de su individualidad y de la constante interacción con los otros.

\section{La familia y su significado}

Al considerarse la familia como una categoría de análisis, no se está pensando en esta como una cuestión meramente morfológica, sino como una entidad que, al estar inmersa en la sociedad, permite conocer la manera en la cual persiste su estructura simbólica; además, las condiciones económicas y sociales del grupo humano al que pertenece la familia en cuestión.

Si se ve a la familia desde las funciones, dígase transmisión de recursos, difícilmente se podrá hacer una lista universal de funciones que sirvan para una definición de unidad doméstica aplicable a todas las sociedades. Sin 
embargo, desde los aspectos morfológicos, nos hallamos ante categorizaciones formales para una explicación de su significado cambiante en el tiempo y entre culturas. Por lo anterior, la definición de familia en el caso de los VA debe abarcar espacios y formas que no obedecen a los esquemas tradicionalmente planteados. Las características de establecimiento de las relaciones de parentesco se tomó como una manera de describir el panorama en el cual se observa la población con la que se trabajó, sin embargo, el eje central lo constituyen las estrategias con las cuales las personas alrededor de la práctica de la venta ambulante se han organizado.

Por otra parte, se analizó cómo es que se perciben las relaciones alrededor de las diferentes funciones dentro del grupo de los VA; además, se prestó atención a cuál es el significado de la organización familiar dentro del grupo de las y los vendedores.

Según Lomnitz (1975), dentro de las dinámicas de los VA aquello de asociar lo femenino al sufrimiento y al sacrificio ya no tiene cabida, pues, en ocasiones, la mujer tiende a desarrollar una personalidad fuerte (capaz de soportar sufrimiento) y a menudo se convierte en el pilar de su familia y mundo social. Es por esta razón que analizar las familias desde los roles tradicionales no permitirá obtener un panorama real de las estrategias que estos desarrollan.

Tal como lo describe Claude Lévi Strauss en su libro Estructuras elementales del parentesco (1981) en los grupos en los cuales la satisfacción de las necesidades económicas descansa totalmente sobre la sociedad conyugal, la alimentación y el bienestar de los miembros depende de esta verdadera "cooperativa de producción". Es así que las actividades productivas de todos los miembros del grupo generan un cambio en las condiciones de este. Es así como las relaciones entre un grupo que trabaja por el bien común se constituyen en una alianza y no solo en una relación meramente legal.

Muchos de los estudios de parentesco han sido enfocados en cómo se establecen las relaciones en la familia y cómo se mantienen de generación a generación, en donde la familia es vista como aquella institución que acompaña los procesos civilizatorios (Piedra, 2007). Por ejemplo, para Radcliffe-Brown (1972), el sistema de parentesco y matrimonio o afinidad puede ser delimitado como una red de relaciones sociales de tipo definido que constituyen parte de toda la red de relaciones sociales o estructura social que tiene su centro en las familias nucleares y sus descendientes, y su adecuado funcionamiento dependerá de dicha estructura.

En las ciencias sociales han surgido interrogantes acerca de las relaciones sociales más cotidianas, como el establecimiento y permanencia de los sistemas de parentesco y su reproducción, ya no se ve la familia en función del matrimonio, sino que se le da valor a cómo las personas se ingenian nuevas formas de hacer frente a la realidad de la que son parte. En la actualidad, cuando se hace referencia al matrimonio, no se está diciendo automáticamente familia porque, aunque en ocasiones es mediante este ritual que se incorporan nuevos sujetos a un grupo social ya existente, no siempre se cumple que las relaciones entre 
las parejas sean permanentes o ritualizadas. Las primeras aluden a que ya no se tiene como referente de matrimonio el "hasta que la muerte los separe"; y las segundas, a que no siempre se da una ceremonia que da pie a la unión conyugal.

La familia es un grupo social que consiste de dos o más personas quienes han contraído un compromiso, ya sea de alianza o consanguínea (relación de alianza es entre marido y mujer; filial es entre padres e hijos y consanguínea entre hermanos) y que puede que compartan un espacio de interacción común. En la actualidad, la idea de familia vista desde la unión conyugal ha sido tema de debate, esto es primordial a la hora de abordar las estrategias familiares de los VA, pues en el inicio debe conocerse cuáles son los conceptos asociados a la familia, las relaciones conyugales y la lealtad.

Las transformaciones experimentadas en las familias, tanto en la estructura como en su forma, obedecen a los cambios sociales y económicos, tales como la inserción de la mujer en el mercado laboral y prácticas más democráticas que ponen en jaque el sistema patriarcal (Piedra, 2007). De esta forma, la estructura familiar puede estar integrada por uno de los padres y los hijos, por la abuela y sus nietos, o por dos personas que sostienen una relación conyugal y sus hijos; en este caso, la familia será vista como un conjunto de relaciones entre las personas que conviven y forman un entretejido de relaciones hiladas por vivencias basadas en la tolerancia y el reconocimiento, lo que antes se denominó alteridad, que en ocasiones comparten ingresos, producción (actividad económica), residencia y transmisión de recursos. De pronto, la estructura familiar está compuesta por figuras que no son padre, madre e hijos: "mis cuatro hijos y yo somos la familia, mi esposo ya no vive con nosotros, mi hijo mayor es quien me ayuda con las ventas" (Estrella, comunicación personal, 19 de junio, 2010). De la misma manera, el sostén económico ha recaído en otras personas: "yo he mantenido a mis dos nietos con este trabajo, mi hija está en Nicaragua" (Auxiliadora, comunicación personal, 19 de junio, 2010).

Derivado de esto, se encontró que las relaciones familiares de las personas participantes en la investigación están en constante negociación con base en la igualdad, hasta cierto punto, y no se piensan desde la base religiosa o cultural del "para siempre", típicos de las sociedades occidentales. Por estas razones, se decidió mirar más allá de las tipologías predominantes en la visión de la población en general, acerca de lo que deberían ser las familias. A partir de ello y preguntándole a Lucía acerca de los roles familiares, ella dice: "Siempre ando en la calle, tengo libertad, lo único es que hay que lavar ropa, pero lo único es de servirle de mujer en la casa y esas cosas, en la casa se dividen las funciones o él con los chiquitos y yo con las cosas o yo con los güilas y él con las cosas" (Lucía, comunicación personal, 30 de marzo, 2011).

Lo que concuerda con la idea de que las familias ya no se miran como si fueran homogéneas, sino que se reconoce la existencia de las particularidades de cada uno de sus integrantes, sus necesidades y la interacción de cada cual desde este espacio particular (Piedra, 2007). La concepción de la familia como instancia social en la que se llevan a cabo las funciones sexuales y procreativas ha cambiado y las personas cada vez 
con mayor frecuencia relegan el tener hijos y ven la familia como un espacio para el crecimiento personal, Lucía en la cita anterior lo define como libertad; es decir, si tuviera una pareja con la que no tuviera que trabajar y tuviera que estar en casa, quizá no se sentiría tan a gusto, ya que desde pequeña ha estado en el ambiente de las ventas y lo considera parte de su identidad como mujer.

Sin embargo, se encontró que los patrones del patriarcado aún están presentes en la idea acerca de la familia en el caso específico de Conrado, quien dice:

La mujer tiene que ser responsable de su casa, nosotros a ella le damos un día libre al mes que ella no hace nada, ella un domingo se tira ahí en la casa, nosotros lavamos, hacemos el almuerzo pero fuera de ese domingo no, si fuera que mi esposa está enferma yo hasta los calzones le lavo, pero si está buena y sana ni una cuchara lavo, es que cada quien tiene su rol en la familia, el padre es el de llevar sustento a la casa, el de la mujer es mantener la casa, y los hijos tienen que cooperar para la familia (Conrado, comunicación personal, 30 de marzo, 2011).

Esto muestra que dentro del grupo de vendedores ambulantes con los que se llevó a cabo la investigación, existen diversas ideas acerca de lo que es la familia y las expectativas que se crean alrededor de los miembros que la componen. Esto puede obedecer a los contextos históricos en los cuales las personas entrevistadas crecieron y por tanto han reproducido ideas en sus familias que en la actualidad son muy debatidas, como lo es el papel de la mujer y su realización personal. Además, como la familia no es un ente aislado, es influida por ideas que la sociedad reproduce como medio de dar uniformidad y para ejercer el control. De alguna manera, puede ser vista como un sistema abierto, en interacción permanente, compuesto a su vez por subsistemas, unos más o menos estables (conyugal, fraterno, y paterno - filial) y otros ocasionales o temporales (según edad, sexo e interés). Pero ambos, persona y familia, están conectados con un suprasistema, el cual puede ser inmediato (barrio, vecindad, comunidad) o más amplio, la sociedad en general (González, 2002). Las familias de los VA están compuestas de madres solteras, abuelas encargadas de sus nietos, parejas, divorciados, solteros, por lo que el sistema es diverso en su composición, por ejemplo con las personas con quienes se trabajó más tiempo; dominan las relaciones conyugales y paterno-filiales. A continuación, se hace una ilustración de la estructura familiar de dos de los casos con los que se logró mejor empatía (Figura 2).

Conrado es hijo de una vendedora ambulante conocida como la Machita, que en la figura 2 aparecen con un reborde al igual que los hijos de Conrado para indicar que aún se dedican a la venta en San José o lo han hecho hasta hace poco. Él está casado, pero su esposa no es vendedora, trabaja para una empresa de limpieza.

La familia de la Machita estuvo compuesta por ella y el padre de sus hijos, ahora están separados, y por sus ocho hijos (cinco hombres y tres mujeres), todos en algún momento tuvieron que ser vendedores para ayudar a su madre; sin embargo, solo Conrado mantuvo este oficio como parte de su realización laboral y 


\section{Genealogía de la familia de Conrado}

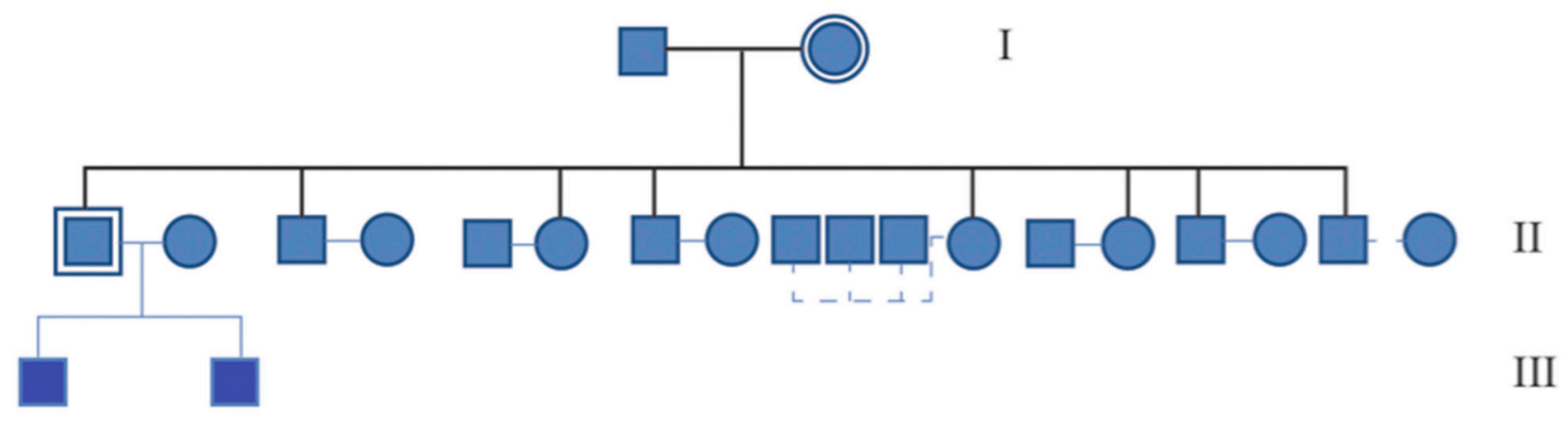

Simbología

I, II, III Generaciones

$\square$ Hombre

Mujer

$\square$ Ego

Hijos del ego

- - Unión libre

Figura 2: Genealogía de Conrado (tomado de Araya et al., 2011).

además es el único que llevó a sus hijos para que le ayudaran los fines de semana. Seis de los hijos se han casado, uno se encuentra en unión libre y una no tiene una pareja estable, aunque ha tenido tres parejas con las que ha tenido hijos.

En la investigación se hace énfasis en la relación paterno-filial, en el caso de Conrado por ser una de las personas que colaboró más con la investigación y debido que es uno de los que se mantiene en la venta ambulante a pesar de los años. Por otra parte está el caso de Lucía (Figura 3):

Lucía también es hija de una vendedora ambulante, tiene 10 hermanos quienes al igual que ella desde niños estuvieron al lado de su madre vendiendo. La atención se centró en Lucía y su pareja Carlos, quienes venden chiles, mandarinas o cualquier otro producto al que tengan acceso. Lo que llamó la atención en este caso es que estaban con sus hijos en la calle vendiendo, el menor de ellos tenía en el momento cuando se 


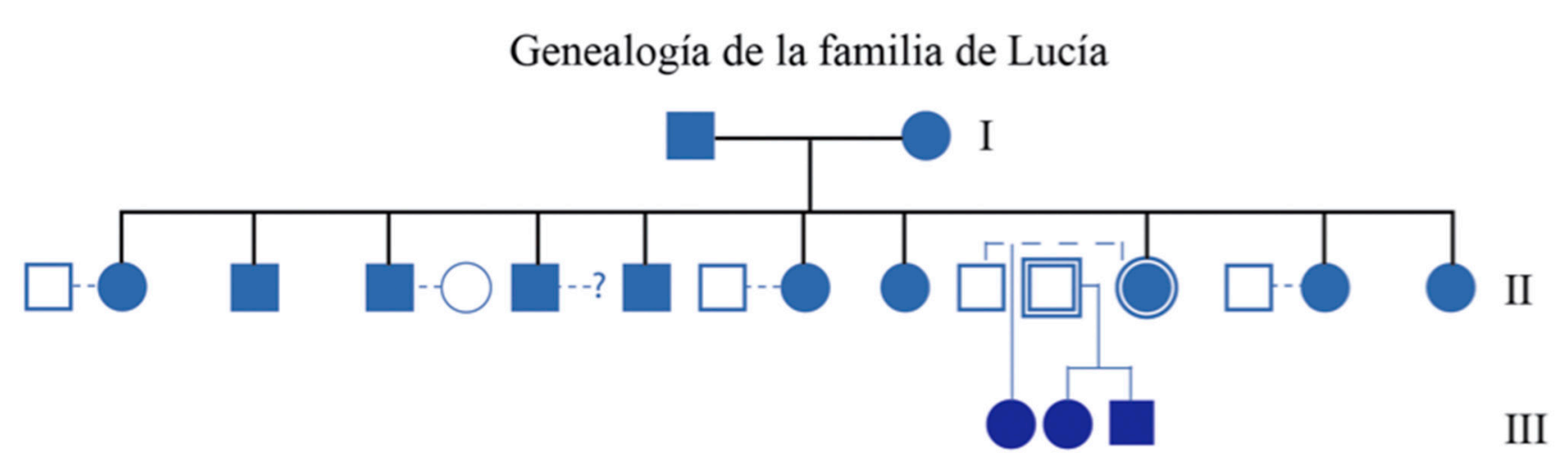

Simbología

I, II, III Generaciones

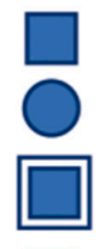

Hombre

Mujer

(Ogo

- Hijos del ego

- - Unión libre

Figura 3: Genealogía de Lucía (tomado de Araya et al., 2011).

finalizó el trabajo de campo siete meses de edad, esta situación fue la que hizo que fueran sujetos idóneos para la investigación. En esta familia (extendida $)^{4}$ prevalecen las uniones libres como manera de establecer relaciones de pareja, lo que puede deberse a la forma en la cual la madre estableció las propias; en la genealogía de Lucía no aparece, pero su madre tuvo diversas parejas e hijos con varias de ellas; sin embargo, no se pudo detallar la información porque Lucía no estuvo dispuesta a discutirlo.

Lo que hace a estas familias sujetos de investigación es que en ambos casos las relaciones estuvieron, en alguna medida, atravesadas por la economía popular y el ejercicio de esta. Se tomó en cuenta el caso de Esperanza por ser ilustrativo de las situaciones de los niños en las calles, ella labora con su esposo en la venta ambulante y su hijo mayor está junto con ellos para mantener a su esposa y su hijo. Además, se tomó

4Es decir, los hermanos(as ) y abuelos que se relacionan con Lucía y su pareja Carlos 
la experiencia de Rosa, quien tiene dos hijos en edad escolar, mas a este caso no se le pudo dar continuidad, pues no se tuvo más contacto con ella. Las anotaciones acerca de ellas se encuentran en el cuarto apartado de este capítulo.

Las relaciones antes descritas están sujetas al ambiente donde nacen y en el cual se desenvuelven, este define sus dinámicas y maneras de ser frente a las diversas situaciones que puedan surgir. En el caso de los VA, la calle es su lugar de trabajo y de constitución de la familia, en ella se diluye su realidad familiar, social, cultural y económica, en medio de las aceras se fortalecen los vínculos y se producen recursos para la subsistencia. Todo en medio de un agitado contexto lejos de la privacidad del hogar o de la comodidad de una oficina.

La realidad que enfrentan los VA en las calles de la capital costarricense les impulsa a desafiar las estructuras establecidas para los roles asignados según el sexo y la edad; para cada familia las condiciones son diferentes, por lo que las dinámicas bajo las que interactúan son de acuerdo con ellas. De tal forma que los jóvenes asumen pronto responsabilidad de ser quienes ayuden al sostenimiento económico de la familia, las mujeres son visibles en medios públicos compartiendo condiciones con sus parejas o solas y los hombres dejan de lado patrones establecidos de lo que deberían de ser y hacer, "desde que estuve en la panza de mi mamá ando en la calle vendiendo" (Lucía, comunicación personal, 30 de marzo, 2011).

En ocasiones, los menores de la familia aportan protagonismo en la escena que se muestra a los ojos de quienes observan, jugando en la acera con las mandarinas, corriendo de una esquina a otra o cuidando a los que aún no caminan y miran a los compradores desde un coche, "ahora mi hijo está aquí conmigo porque después de que va al kínder no tengo con quien dejarlo, él se queda dentro de esta tienda mientras estamos aquí afuera vendiendo el culantro" (Esperanza, comunicación personal, 10 de marzo, 2011). Lo anterior puede ser ilustrado con una fotografía tomada en el lugar de trabajo de los vendedores (Figura 4).

Aunque podría esperarse que la calle signifique un ámbito poco humanizado, debajo de la lluvia y del sol se esconden miradas, gestos y manifestaciones de solidaridad con ese otro que se vuelve cercano en la distancia.

En razón de estas situaciones, se maneja en forma incesante en el lugar de trabajo de los VA una situación de normalidad-anormalidad (venta-decomiso), función-disfunción (policía-inseguridad), vida-muerte (alimentación-golpes), mente-cuerpo (ánimo- cansancio) (González, 2002). El uniforme que utiliza la Policía que a cualquier otro ciudadano podría darle seguridad a ellos les genera prevención, por no llamarlo miedo.

Desde estas dualidades es que se ejecuta la venta ambulante, diluyendo constantemente las fronteras entre lo público y lo privado entre lo formal e informal, y las familias se componen de nuevos miembros, que lo que les da cohesión son esas nuevas fronteras donde no solo la sangre les hace uno, sino que la realidad del día tras día es lo que los cobija bajo las mismas expectativas y estrategias. Estas dualidades 


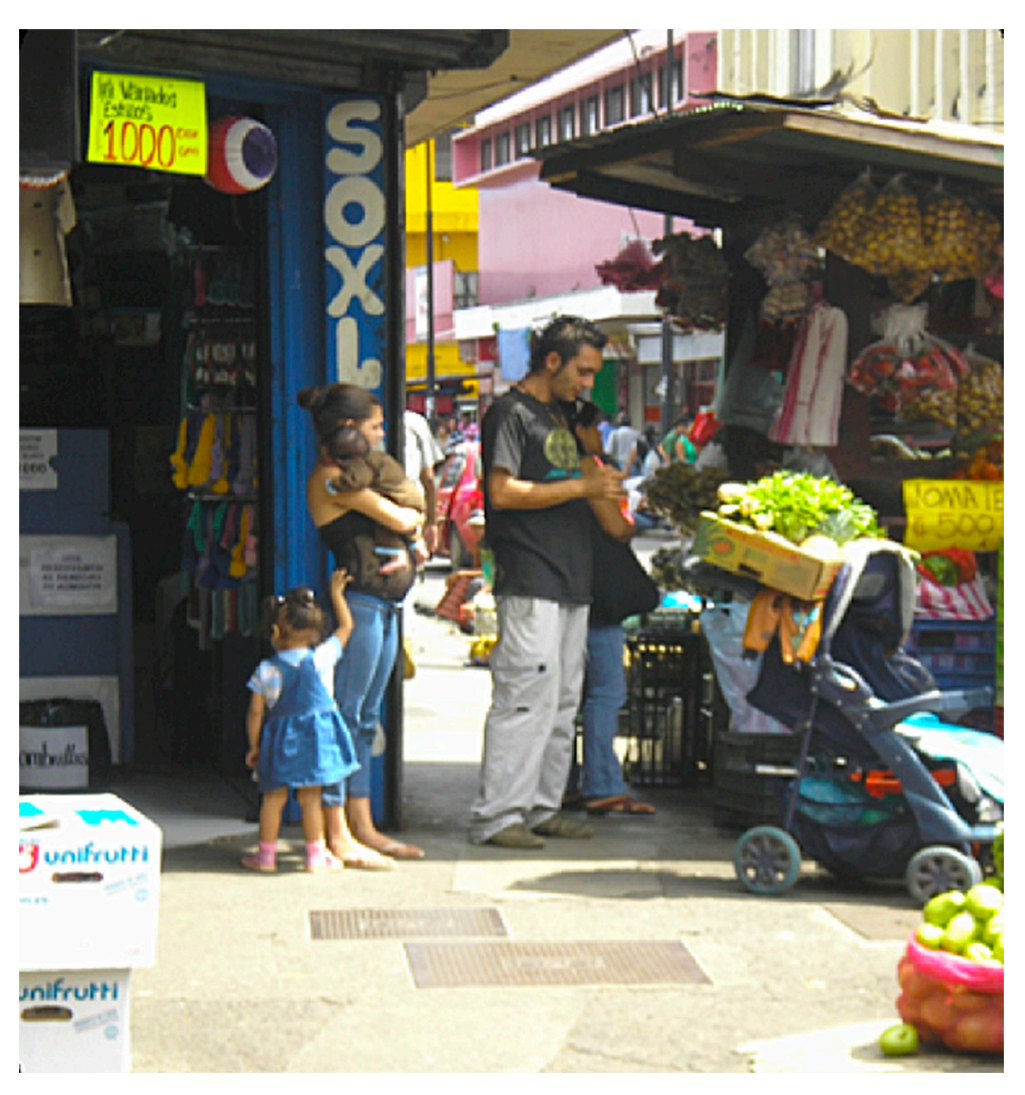

Figura 4: Familia de vendedores ambulantes (tomado de Araya et al., 2011).

pueden expresarse en las formas en las cuales los VA se relacionan con los actores del contexto; por un lado, mientras uno de los vendedores afirma que puede vender sin problemas en el lugar en el que se encuentra; por otro, camina con la caja de manzanas al hombro porque se está ejecutando un decomiso y expresa que el asunto es que la policía no los deja en paz. Aquí la figura de la policía no es un ente de seguridad, sino de riesgo ante la posibilidad de perder la mercadería.

Algunos de los vendedores dicen que serlo les gusta, sin embargo, en ocasiones se les ve apesadumbrados por las situaciones enfrentadas a diario con la policía y con la imagen socialmente asignada; no obstante, cuando se les interroga acerca de su opinión de ser un VA, se expresan positivamente de la actividad. Dándose un contraste entre lo que se muestra al exterior y lo que se dice. 
Dichas situaciones hacen que los miembros de las familias estén en constante comunicación, las alertas son su ir y venir, idean formas de cargar la mercadería, hoy en los hombros; mañana las arrastran en la caja de plástico por calles en donde es menos difícil que los alcancen. Lo que puede ocurrir es tan variado que hay que estar preparado para todo en cualquier momento, sea bueno o no tanto.

La falta de recursos para acceder al sistema económico validado socialmente puede constituir una limitante para las familias de VA; aunque visto desde la economía popular, esta misma falta de recursos puede que no solo tenga consecuencias negativas, sino que está relacionada también con procesos de reacomodo del desarrollo familiar, pues al no tener formas legítimas de inserción, la venta ambulante se convierte en su medio para garantizarse los recursos de subsistencia, como parte del ingenio que nace en condiciones adversas. Es ahí donde las condiciones o falta de ellas hace que dentro de una familia de VA, las adversidades se trasformen en fuente de crecimiento, cambio, y desarrollo según las capacidades de cada uno de los miembros (González, 2000).

Por sí solo, un evento o condición puede que no genere desequilibrio dentro de un grupo familiar, depende del significado que se le otorga y de la capacidad adaptativa de la familia. Dicha capacidad es la que hace que sea importante contar con lazos estrechos basados en la reciprocidad dentro de la economía popular, pues proveen un soporte emocional y económico para la ejecución de la práctica.

Creo que las familias son personas que se necesitan unas a las otras, que se ayudan en lo que puedan, que estén pendientes de lo que necesita una a la otra, que ayude hasta lo más allá (Lucía, comunicación personal, 30 de marzo, 2011).

Sí me siento apoyado por ella (por su esposa), además si me dice que deje el trabajo no lo voy a hacer porque esto me gusta además ella me conoció aquí y aquí creo que me voy a morir, ella nunca se ha metido con el trabajo (Conrado, comunicación personal, 30 de marzo, 2011).

En el caso de los VA, la familia se convierte en un recurso con el que cuenta para desarrollar la dinámica misma de la venta, la ayuda de varios de los miembros facilita la interacción en diferentes escenarios: doméstico, comunitario y de trabajo. Esto dado que en el caso de Lucía en la misma cuadra en la que ella se encuentra se hallan también varios de sus familiares, siendo una red de apoyo para los momentos de los decomisos, almuerzos, para estar atentos de los niños o simplemente para ir al baño. En la figura 5 aparece Carlos junto con el padrastro de Lucía, él le entrega el cambio de un billete en monedas para que pueda dar los vueltos a los clientes. 


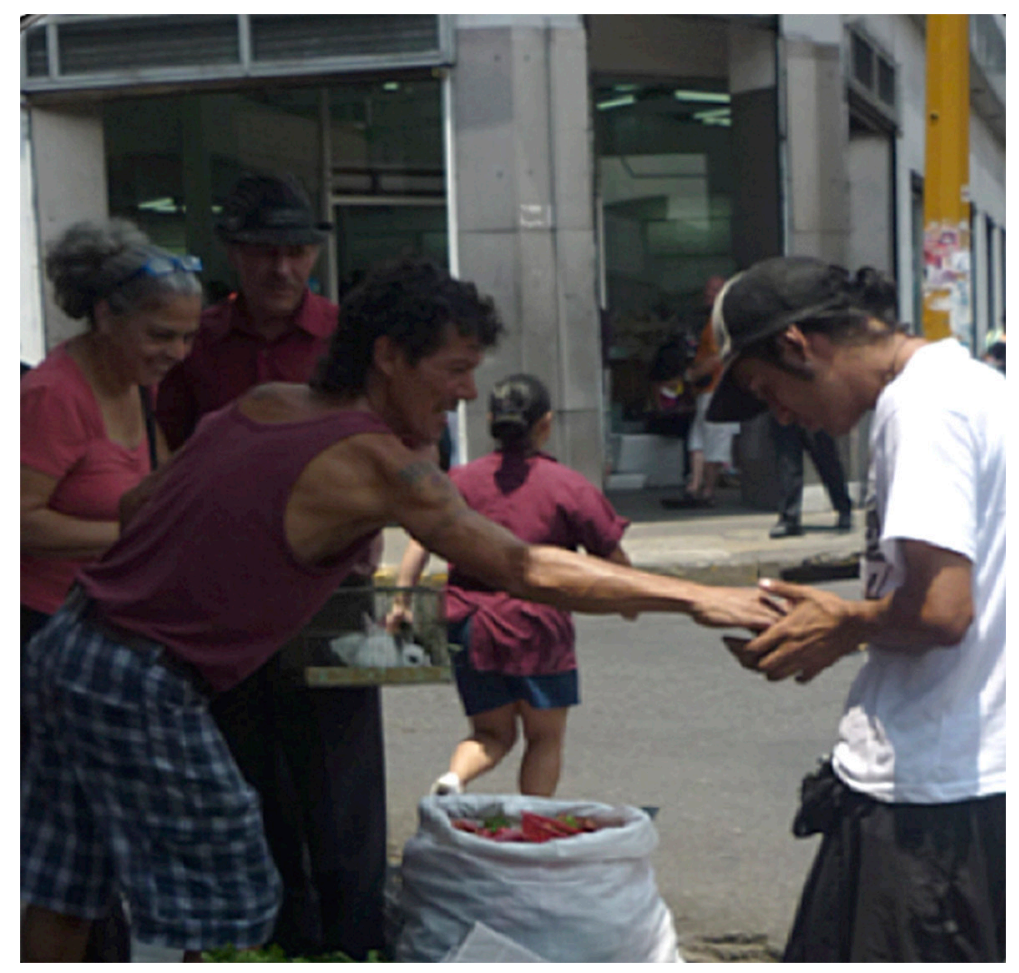

Figura 5: Carlos en su puesto de trabajo (tomado de Araya et al., 2011).

\section{Conclusiones}

Para los VA se conoció que las familias de cada uno de los entrevistados jugó un papel importante en la elección de la economía popular como su medio para obtener los recursos necesarios para la subsistencia, asociando la venta ambulante a valores familiares como la honestidad y el sacrificio y la responsabilidad que la hacen una actividad digna y válida para sí mismos.

La información recabada coincide con el hecho de que ciertos individuos y grupos pequeños, debido a circunstancias económicas y políticas específicas una vez dentro del grupo asimilante (en este caso San José), llegan a cambiar su localidad, su patrón de subsistencia o su pertenencia a una familia (Barth, 1976).

Las familias de vendedores ambulantes en su aspiración de participación en los sistemas sociales más amplios tienen varias opciones: 1) pueden tratar de incorporarse a la sociedad industrial; 2) pueden aceptar su estatus de "minoría" e intentar reducir sus desventajas interactuando desde dicha aceptación con el sistema mayor; 3) pueden optar por acentuar su identidad étnica y utilizarla para desarrollar nuevas posiciones y patrones que organicen sus actividades (Barth, 1976). 
En el caso de los vendedores ambulantes, podrían calificarse como innovadores culturales que, poniendo en práctica estrategias que tienen éxito, brindan diversificación a lo interno del sistema mayor que les permite subsistir, estas estrategias son, de paso, las ventas en sí mismas, su dinámica de interacción clientevendedor y su manera de encontrar fisuras en los sistemas formales que les permiten obtener los recursos para su subsistencia.

Se puede decir que la base para los dilemas de los VA radica en que para obtener los bienes materiales y sociales que aprecian, y para compartir las oportunidades existentes en la sociedad, se ven obligados a suprimir o difuminar las características que la sociedad a enmarcado como no deseadas (Eidheim, 1976). Después de estar en contacto con las familias de VA, se visualiza que la construcción de la alteridad nace desde el extrañamiento del otro, distinto, pero cercano, tiene discursos e identidad diferentes de la de los demás miembros, que aunque esas diferencias están presentes mediante la conciliación, se logra una convivencia más o menos armónica. Lo que importa es cómo actúan los otros en cuya compañía se interactúa y con los cuales se es comparado y qué identidades alternativas y conjuntos de normas están disponibles para el individuo (Barth, 1976). Así es que un miembro logra comprender las ideas y las creencias de los de su familia y se construyen nuevos discursos legítimos en los cuales se interioriza aquello que cada uno considera como válido y se relega lo que no lo es, resultando de ello un discurso nuevo con el que la mayoría de los integrantes del grupo familiar se siente a gusto.

Esa alteridad es, además, la manera ética y moral de convivir con los demás, es donde el respeto por las diferencias y la búsqueda de conciliación entre lo que se espera del otro y lo que realmente hace juegan un papel preponderante. La alteridad es el trato con el otro, "mi relación con el otro" igual, pero distinto, que incluye la capacidad de reconocerle y responsabilizarse de quién es, de lo que hace o desea. De ese proceso de re-conocimiento del otro se da cabida a la reproducción de valores, lealtades, mitos y rituales que permiten la cohesión de la familia, es aquí donde la elección de la actividad económica se da por la predisposición de algunos de los miembros más influyentes de la familia hacia ciertas actividades que, aunque no son reconocidas socialmente como válidas, para ese grupo familiar a representado un modo de vida que les ha permitido subsistir a lo largo de los años y que ante sus ojos es un trabajo y no una actividad fuera de la norma.

En esencia, la marginalidad reduce la capacidad de ganar acceso a las instituciones y procesos urbanos: educación, empleo adecuado, servicios, vivienda, bienes de consumo, estatus social, contactos con organizaciones e influencia política. Este proceso depende no solo de las relaciones (endógenas) de un grupo familiar, sino que, además, la producción de alteridad se haya influida por las relaciones (exógenas) presentes en los sistemas que rodean la familia siendo la comunidad, el barrio y la sociedad misma quienes juegan en la conformación de las diferentes formas de concebir e interiorizar al otro. Por lo anterior es que se plantea que para comprender el caso de los VA es imperativo despojarse de la mirada de la exclusión impuesta por 
el discurso dominante desde el cual se le ha dado a los vendedores el lugar del extraño, imagen que está dada desde diferentes estigmas. El VA se convierte, por lo tanto, en ese ser lejano que infunde temor y falta de confianza, potenciando el rechazo dentro del conjunto social.

\section{Referencias bibliográficas}

Alejos, J. (2006). Identidad y alteridad en antropología dialógica. En J. Alejos (ed.), Dialogando alteridades. Identidades y poder en Guatemala (pp. 17-38). México D.F.: UNAM.

Araya, G., Mejía, M., Solís, N. y Vega, K. (2011). Experiencias, vivencias e identidad de quienes se dedican a la venta ambulante de frutas y verduras, ubicados en las calles 6 y 8 del casco urbano central de San José, 2010-2011 (Tesis de licenciatura inédita). Universidad de Costa Rica, San José, Costa Rica.

Barth, F. (ed.) (1976). Los grupos étnicos y sus fronteras: La organización social de las diferencias culturales. México: Fondo de Cultura Económica.

Eidheim, H. (1976). Cuando la identidad étnica es un estigma social. En F. Barth (ed.), Los grupos étnicos y sus fronteras: La organización social de las diferencias culturales (pp. 51- 52). México: Fondo de Cultura Económica.

González, I. (2000). Las crisis familiares. Revista Medicina General Integral, 16(3), 280-6.

González, C. (2002). Teoría estructural familiar. Medicina de Familiares. Recuperado de http://www. medicinadefamiliares.cl/Trabajos/teoriaestructural.pdf

González S, F. (2007). Salud mental a nivel familiar desde la perspectiva de alteridad. Psicología desde el Caribe, 20, 1-27.

González S, F. (2008). Hacia una visión de alteridad en familias con pobreza económica. Ciencia y Sociedad, XXXIII(3), 388-404

Krotz, E. (1994). Alteridades y pregunta antropológica. Alteridades, 4(8), 5-11.

Lévi, C. (1981). Las estructuras elementales del parentesco. Barcelona: Editorial Paidós.

Lévinas, E. (1993). Entre nosotros: ensayos para pensar en otro. Valencia: Editorial Pre-Textos.

Lomnitz, L. (1975). Cómo sobreviven los marginados. Mexico: Siglo XXI Editores.

Piedra, N. (2007). Transformaciones en las familias: análisis conceptual y hechos de la realidad. Revista de Ciencias Sociales, 116, 35-56.

Radcliffe-Brown, A. (1972). Estructura y función en la sociedad primitiva. Barcelona: Península. 